This item was submitted to Loughborough's Research Repository by the author.

Items in Figshare are protected by copyright, with all rights reserved, unless otherwise indicated.

\title{
Cognitive enhancing drugs in sport: Current and future concerns
}

PLEASE CITE THE PUBLISHED VERSION

https://doi.org/10.1080/10826084.2020.1775652

PUBLISHER

Taylor and Francis

VERSION

AM (Accepted Manuscript)

PUBLISHER STATEMENT

This is an Accepted Manuscript of an article published by Taylor \& Francis in Substance Use \& Misuse on 11 Jun 2020, available online: https://doi.org/10.1080/10826084.2020.1775652

\section{LICENCE}

CC BY-NC-ND 4.0

\section{REPOSITORY RECORD}

Smith, Aaron, Constantino Stavros, and Kate Westberg. 2020. "Cognitive Enhancing Drugs in Sport: Current and Future Concerns”. Loughborough University. https://hdl.handle.net/2134/12497858.v1. 


\section{Introduction}

Drugs have been embedded in sporting culture for most of the 20th century and now, two decades into the $21^{\text {st }}$ century, elite sport is firmly associated with a diverse concoction of illicit, prescription, and over-the-counter substances, many of which can be classified as performance-enhancing drugs (PEDs). Few topics in sport elicit such vehement opinions and vigorous debate, especially when it comes to the best policies and interventions for eliminating, containing, or reducing the use of PEDs. The last decade has seen a healthy research agenda materialise around sport doping, accelerated by a constant stream of new drugs and substances available to athletes (Smith et al., 2018). One less well researched but increasingly important issue concerns the escalating use of cognitive enhancing drugs (CEDs) (Garasic \& Lavazza, 2016). The following commentary aims to provide a more nuanced understanding of CEDs in elite sport by considering the use, scale, efficacy, risk and impact of CEDs. This commentary subsequently locates CED use within a sport policy context before examining its specific applications and the complexities pertaining to use by athletes.

High performance athletes operate within a pressurised environment that demands continuous improvement, tends to glorify winning at all costs and, at some professional and elite levels, can deliver considerable financial rewards. Indeed, the use of CEDs has been flagged by sport governing authorities such as the World Anti-Doping Agency (WADA), which has included a suite of pharmaceutical CEDs on their list of banned substances. In addition, a growing number of CEDs cases in professional sporting leagues have been reported in the media going back more than a decade. For example, in 2013, National Football League (NFL) player, Richard Sherman, claimed that his positive test for the attention deficit hyperactivity disorder (ADHD) drug (and CED) Adderall, was inaccurate and overblown, commenting to the media that a 'bunch' of other players were taking it (Patra, 2013). In another NFL case, Kenny Vaccaro was suspended for Adderall use but 
maintained that it did not enhance performance. Meanwhile, Major League Baseball has granted 91 exemptions for players taking medication such as Adderall and Ritalin to treat ADHD. This figure equates to approximately $10 \%$ of players compared with usage in the general population of about 4\%, although this number has been dropping since 2008 (Adler, 2018). At the same time, other sports bodies have also acknowledged the potential attraction of CEDs. The International Mind Sports Association, the regulatory body overseeing bridge, draughts, go, and xiangqi, has signed up to WADA's prohibited substances policy. Similarly, esports bodies like Electronic Sports League (ESL) have instituted similar bans in response to widespread fears of cognitive doping no doubt prompted by comments such as champion player, Kory Friesen's YouTube declaration that all the players were on Adderall (Gilbert, 2015). More recently, former WADA Director David Howman described esports as a doping 'wild west' (Baldwin, 2019).

The governing authorities of other competitive games / sports involving heavy cognitive demands also seem to recognize the potential misuse of cognitive enhancing drugs. For example, the Fédération Internationale des Échecs (FIDE), which oversees national chess federations and acts as the governing body of international chess competition, is a signatory to the WADA Code (FIDE, 2018). They have worried about the effects of CEDs since 2014, when they first signed up to the anti-doping code, a concern that has heightened more recently since a controlled trial by scientists showed that the CEDs, modafinil, methylphenidate, and caffeine can improve chess play (Franke et al., 2018). Likewise, at the 2014 World Bridge Federation (WBF) Executive Council meeting, the WBF accepted the revised Anti-Doping Code from WADA. As a result of new testing, in 2018, the authority's Anti-Doping Hearing Panel, found world number one ranked player, Geir Helgemo, guilty of an 'Anti-Doping Rule Violation'. Curiously, the sanction was for testosterone, but the violation only strengthened the body's concerns over the prospective usage of CEDs as well. 
Cognitive enhancement appears to be a relatively new challenge for anti-doping policy makers in sport (Cakic, 2009). Although few statistics offer concrete insight into the extent of CEDs use, the anonymous web-based Global Drug Survey captured levels of pharmacological cognitive enhancement (PCE) use (non-medical use of methylphenidate, modafinil, dexamphetamine [Adderall], cocaine, illegal amphetamine, and illegal methamphetamine) among 100,000 non-ADHD individuals across 15 countries. The survey concluded that illegal stimulants and modafinil use had increased across all countries from $3.2 \%$ in 2015 to $6.6 \%$ in 2017 . These PCEs were also rated the highest in terms of perceived effect on cognitive performance (Maier, Ferris \& Winstock, 2018).

CEDs are prescribed in the treatment of neuro-degenerative disorders such as Alzheimer's and Parkinson's disease, and are also employed to curb the unfavourable symptoms that arise with conditions affecting cognitive development, the most prominent being attention deficit hyperactivity disorder (ADHD) (Volkow et al., 2012). Studies investigating the use of CEDs for non-medical cognitive enhancement have provided varying estimates of usage rates, ranging from $2.4 \%$ in the general population (Partridge, Lucke \& Hall, 2012), to $20 \%$ amongst certain professions (Maher, 2008).Within select university / college student groups, estimates have been as high as 55\% (Smith \& Farah, 2011). Although the empirical evidence remains inadequate for making decisive statements about the demographic profile and scale of use, there is enough evidence to point to a growing consumption of CEDs, with most non-medical use premised on their putative ability to enhance alertness, creativity, concentration, memory, and problem-solving.

In the broadest schema, CEDs include legal over the counter substances (e.g., coffee and other caffeinated drinks), controlled medications used without a medical condition (e.g., Ritalin, Adderall, modafinil [PCEs]) and illegal drugs (e.g., cocaine, ecstasy, crystal meth) (Dietz, Soyka \& Franke, 2016), that lead to some form of cognitive enhancement. 
Enhancement can be distinguished from other uses of CEDs (e.g., treating psychiatric conditions) by a primary focus on functionality and performance improvement (Wolff \& Brand, 2016), either directly (e.g., improved concentration during a task) or indirectly (e.g., improved mood regulation for work) without medical need (Franke et al., 2014). Use may not necessarily be motivated by outperforming competition as it can also be triggered through a maladaptive stress coping mechanism (Vargo \& Petróczi, 2016). Given the uptake in nonmedical usage supported by positive media coverage (Garasic \& Lavazza, 2016), the use of CEDs for cognitive enhancement presents legal, social and ethical challenges to sport (Sahakian et al., 2015).

Although far from quick fixes and magic pills, a range of lifestyle activities and cognitive exercises have also been associated with improved mental acuity, including physical exercise, dietary supplements like certain fats, sleep techniques, meditation, yoga, music, electronic simulations, and so-called 'brain training focal techniques' (Sachdeva, Kumar \& Singh Anand, 2015). These activities, exercises and supplements are diverse and likely to require scrutiny in their own right, however this commentary will purposefully contain itself to the complexity of substances designed to influence neurotransmitters, neural signalling molecules, and neuropeptides, as classified under 'pharmaceuticals' in the Dressler et al. (2019) dimensions of cognitive enhancing strategies taxonomy, also referred to as pharmacological cognitive enhancement (PCE) drugs. Our interest here is therefore primarily concerned with prescription drugs designed to offset cognitive impairments but used by healthy athletes to prime decision-making, amplify situational awareness, and attenuate mental fatigue. As a result, although CEDs were developed for medical interventions, we consider their application in this context as a form of 'neuro-enhancement' (Frati et al., 2015), or as it is sometimes described, 'cosmetic neurology' (Chatterjee, 2007). For the purposes of this commentary, we will focus on the use of pharmacological drugs by healthy 
individuals for cognitive enhancement through action on the brain's biochemical composition (Vrecko, 2013).

The non-medical use of controlled medical substances is purported to lead to cognitive enhancement through their interaction with a myriad of chemical neurotransmitters (e.g., dopamine) (d'Angelo, Savulich \& Sahakian, 2017). For example, summary data from a systematic review suggest that in healthy non-sleep-deprived individuals, modafinil increases performance in complex cognitive tasks (Battleday \& Brem, 2015). However, the efficacy of CEDs for non-medical enhancement is contentious. In contrast, another systematic review of psychostimulants, including controlled medications, found mixed evidence for non-medical cognitive enhancement in healthy individuals, although conclusions were limited by the lack of randomised placebo-controlled trials (Fond et al., 2015).

One of the aims of this commentary is to consider the non-medical self-administration of CEDs in sport, especially since their performance application is less obvious than PEDs. The potential use of CEDs for illegitimate advantage has not gone unnoticed by the global anti-doping authority WADA. Concerned that athletes might employ CEDs to gain an unnatural edge, WADA has classified many of the prescription drugs associated with cognitive enhancement as competition prohibited stimulants (WADA, 2020).

Despite this interest from WADA, the extent of CEDs use in sport at any level remains largely unknown. Yet, if the media-led hype were even partially accepted, athletes at all levels — and especially in elite sport—could easily be seduced by the promise of improved learning, better decisions, reduced anxiety, superior relaxation, and higher performance under pressure. However, not only is it uncertain whether CEDs actually deliver these benefits (Advokat \& Scheithauer, 2013), their other effects are also under-specified. It is possible, for example, that CEDs could cause unintentional reactions in an athlete's emotional state or 
incur other presently unrecorded side-effects. Despite the uncertainty, the future is likely to bring with it more potent CEDs, and consequently greater incentive to use them in sport.

A challenge in developing sport anti-doping policies is that the efficacy, health and ethical implications of cognitive enhancement is highly contentious within the medical and sporting communities, and some foundational understanding is necessary to allow for deeper debate. Their acceptance both inside and outside of elite sporting competition also seems fluid. For example, one study revealed that the general public is twice as likely to accept the use of cognitive enhancers compared to performance enhancing drug use by athletes, although the levels of acceptance in both cases remain relatively low (Partridge, et al., 2012). One recent study revealed that in the general population, support for the use of cognitive enhancement drugs was higher for employees undertaking professional and work duties than for students or athletes (Conrad, Humphries \& Chatterjee, 2019). Part of the challenge lies with an inadequate understanding of what CEDs are, how they are used, and whether they do deliver non-medical cognitive enhancements.

\section{What are Cognitive Enhancing Drugs and How do they Work?}

With thanks to its popular appellation, 'nootropics', from the Greek term meaning 'acting on the mind' (Froestl et al., 2012), CEDs have become associated with a vast suite of reputed benefits including better learning and retention, resistance to impairment, information integration, and mental control, all without the unhelpful, mind-altering side-effects that tend to go with neuro-psychotropic drugs (Giurgea \& Salama, 1977). For the most part, a handful of prescription drugs comprise the basis for these claims, many of which remain unsubstantiated or contentious. For example, one prominent CEDs class includes the drug modafinil, commonly prescribed for sleep disorders such as narcolepsy. Psychostimulants for treating ADHD comprise a second common CEDs class and include drugs like 
methylphenidate or mixed amphetamine salts with dextroamphetamine. Alzheimer medications, such as donepezil, also feature as common CEDs (Partridge et al., 2011).

The brain mechanisms through which CEDs work are unclear as well as whether they work at all for healthy users seeking augmentation. More is understood about the way CEDs attenuate medically diagnosed cognitive deficits, although there are numerous possibilities given the range of drugs each targeting different cognitive limitations. One review identified 19 types of impact, dependent upon the ways each class affects cognition (Froestl et al., 2012). Drug classes were categorised according to their principle brain interaction mode, such as through receptors, enzymes, or reuptake transporters. An example of a better understood drug is methylphenidate, a stimulant related to amphetamine (De Jonge et al., 2008). Acting as a catecholamine reuptake inhibitor (Franke et al., 2017), methylphenidate improves concentrations of dopamine and noradrenaline by blocking their reuptake (De Jonge et al., 2008). Higher levels of dopamine have been linked to superior performance in working memory and attention (Husain \& Mehta, 2011), both of which would seem to be advantageous to athletes engaging in sports that demand high levels of focus across a complex field of dynamic variables. Putatively, players of concentration sports like shooting, archery, darts and esports could benefit, as would those participants involved in the retrieval and recognition of strategic patterns, from fast-moving sports like ice-hockey to more introspective games like poker and chess. It is also worth keeping in mind that CEDs could play a part in mental preparations prior to events as well as on-field decision making itself. An off-field amplification in cognitive performance could prove advantageous in sports involving substantial between game and pre/post performance analysis. Examples might include activities such as memorising detailed team and opponent playbooks, the analyses and interpretation of vast swathes of playing footage, and holding a detailed mental inventory 
of team and adversary strengths and weaknesses. Such off-field applications of CEDs reinforce the significance of regular out of competition testing by sport authorities.

It is also plausible that coaches and managers might find the use of CEDs attractive, especially in the absence of any direct anti-doping testing regime. Coaches, advisors and team managers stand to benefit from cognitive enhancement both during training and performance, given the strategic nature of their work in concert with the need to think fluidly and adapt swiftly. The possibility that an athlete or team could receive an advantage via a CED-doping coach adds a further level of policy complexity for sport regulators like WADA and professional leagues. Extending testing to the entire support entourage of a team or athlete poses a suite of complications, including who is to be subject to tests, the escalation of testing costs, consideration of privacy issues, and whether certain sports or events are exempt. A further problem could be the treatment of officials, whose cognitive performances are pivotal to their accuracy. Perversely, teams, athlete and fans might even wish to advocate for officials to use CEDs in order to reduce the incidence of poor judgements that could disadvantage competitors and undermine parity.

The mechanisms through which some CEDs work are less well understood (de Jonge et al., 2008). For example, the sleep disorder drug modafinil may similarly influence the reuptake of dopamine (Repantis et al., 2010), but might also affect levels of norephinephrine, as well as neurotransmitters including serotonin and glutamate (Franke et al., 2017). The glutamate link resurfaces with drugs possessing a common pyrrolidone structure, classed as racetams. Like their parent piracetam, racetams bolster cognitive deficits by augmenting glutamate receptor performance in neurons (Copani et al., 1992). In lay terms, glutamate receptors send signals between nerve cells; they mediate the communication between brain cells (or neurons). In theory, enhancement would facilitate improved learning and memory, in the same way stimulants like caffeine work. Notwithstanding uncertainty about how they 
work, if the trend from PEDs in sport extends to CEDs, then we might reasonably anticipate a future with more products, greater effects, increased usage, and higher dosages (Cakic, 2009; Farah et al., 2004).

\section{CEDs Research: Establishing the Facts and Gaps}

\section{Usage Rates}

Research revealing the demographics, motivations, scale and contexts of CEDs usage are fragmented, offering only glimpses into a consortium of diverse populations. Specific data concerning athletes at any level is almost entirely absent, making conclusions impossible to draw. A first challenge lies in establishing general usage rates, chiefly because of the difficulty in separating legitimate prescription use from attempts at cognitive enhancement or recreational use (Smith \& Farah, 2011). Studies focusing on the cognitive effects of stimulants are available but they do not consider usage for non-medical purposes.

A study conducted by the journal Nature reported that $20 \%$ of its readership had employed CEDs for non-medical purposes (Maher, 2008), although the sampling procedure was problematic, having relied on self-selection. Survey results from an Australian sample found far more modest usage levels; only $2.4 \%$ of adults confirmed their use of CEDs in order to aid concentration or alertness, while $8 \%$ claimed to know of others who took CEDs for similar reasons (Partridge et al., 2012). However, CEDs as 'smart drugs' for students have attracted more empirical interest than any other context.

Perhaps the most attention has been directed towards the drug methylphenidate, more commonly known under one of its trade names, Ritalin. Developed to combat symptoms associated with ADHD, the drug has become renowned as the most popular smart drug for students (Franke et al., 2010; Maier et al., 2013). This cohort appear to gravitate towards 
CEDs given their promise for accelerating learning, attenuating fatigue, diminishing anxiety, moderating stress, and improving relaxation and sleep (Maier et al., 2013).

A meta-review of studies revealed significant variability in the prevalence of CEDs usage with lifetime non-medical use of stimulants by students ranging from $1.7 \%$ to $55 \%$, the latter in a sample of university students connected to fraternities (Smith \& Farah, 2011). For example, German high school and university students reported a lifetime use of non-medical prescription stimulants of $1.2 \%$, while a corresponding Swiss study found usage at $7.6 \%$ (Maier, Liechti \& Schaub, 2013). Likewise, data from New Zealand returned 6.6\% (Ram et al., 2016), while the level in the United States was reported at 9.5\% (McCabe \& West, 2013). A study of Australian university students indicated a $6.3 \%$ lifetime use of prescription CEDs for enhancement purposes (Riddell, Jensen \& Carter, 2018).

\section{Athlete and Sport Use}

Because some CEDs induce strong emotional responses including feelings of well-being and even euphoria, they may not be employed by athletes for either medical intervention or cognitive enhancement (d'Angelo et al., 2017). Recreational use of these substances by athletes is not necessarily more prevalent than other illicit drugs that enhance perceptions of mood, relaxation or recovery, but there is some suggestion that certain CEDs restrict appetite and are therefore of benefit to athletes competing in weight categories or in sports where power to weight ratios influence performance, such as horse-racing or gymnastics (Smith \& Farah, 2011). It is possible that the primary motivation for use may be more to do with an emotional uplift and general pleasure-seeking (Vrecko, 2013) than cognitive performance. Athletes could find both sets of impacts seductive. Some evidence points to a 'work hard, play hard' ethos in sport that can lead athletes to consume relatively more recreational and illicit substances than their non-sporting counterparts (Peck, Vida \& Eccles, 2008; Wichstrom 
$\&$ Wichstrom, 2009). Furthermore, studies of college athletes have depicted a higher rate of substance use and risky behaviour than college non-athletes (Wilson, Pritchard \& Shaffer, 2004).

A study of German recreational triathletes reported that $15 \%$ had experimented with CEDs such as modafinil and methylphenidate (Dietz et al., 2013). A worrying correlation indicated that $13 \%$ of the triathletes also employed variants of anabolic-androgenic steroids (AAS). These studies at least hint at the possible attraction for athletes — and coaches/managers - in taking CEDs. They also foreshadow the considerable interest in the use of phenethylamine stimulant Adderall in esports (Holden et al., 2017).

\section{Evidence for CEDs Efficacy}

Making the investigation of CED more complex, the type of cognitive task, dosage, patterns of use, environmental influences and psychological and physiological state all blur assessment of CED effectiveness (Advokat \& Scheithauer, 2013; Bagot \& Kaminer, 2014; Caldenhove, Sambeth, Sharma, Woo \& Blokland, 2018; d'Angelo, Savulich, \& Sahakian, 2017; De Jongh, Bolt, Schermer \& Olivier, 2008; Ferretti \& Ienca, 2018). Further, CEDs often do not provide the level of effect sought or expected by users (Repantis, Schlattmann, Laisney, \& Heuser, 2010). Supporting this position, Caviola and Faber's (2015) comparative review of evidence for pharmacological (e.g., CED) and non-pharmacological cognitive enhancement (e.g., sleep, exercise, computer training) concluded that, 'currently available PCE [pharmacological cognitive enhancement] and NPCE [non-pharmacological cognitive enhancement] techniques can enhance human cognition to a significant, albeit moderate degree and that both are subject to moderating variables' (p.5). What is most significant about the findings of Caviola and Faber's review is not that claims for the effects of CED 
should be tempered, but that users erroneously perceive CEDs will provide a quick and noticeable enhancement; a supposition that does not align with the nascent evidence.

A recent study on skilled chess players employing modafinil and methylphenidate (as well as caffeine), reported a positive cognitive enhancing effect (Franke et al., 2017). Curiously, despite the expected intensification impact of using stimulants, the participants made slower but better decisions, perhaps because they were able to undertake more complex calculations. At least one other study, utilising healthy volunteers, also reinforced the speedaccuracy trade-off the chess players putatively experienced (Winder-Rhodes et al., 2010). These studies have added weight to sceptics' claims that CEDs impact on psychometric testing is not transferable to chess due to the game's inherent cognitive complexity (Mihailov \& Savulescu, 2018). The results of the preceding studies also raise complications for athletes operating in time-constrained environments where better but slower decisions are seldom appreciated. However, if CEDs can stabilise a surgeon's hand, it is not a distant supposition that they may also steady the hand of a competitive shooter or archer (Santoni de Sio, Faulmüller \& Vincent, 2014). Another strand of uncertainty for athletes is the potential for methylphenidate to reduce inhibitory behaviours leading to more frequent high-risk decisions, an outcome that could work with or against an athlete (Campbell-Meiklejohn et al., 2012).

Putting aside the effectiveness of CEDs for legitimate medical treatment, a modest series of studies have considered the effects of modafinil, Adderall and Ritalin on healthy individuals in non-therapeutic contexts. Reports vary, but evidence has linked modafinil with improved spatial memory and better visual pattern recognition (Randall, Shneerson \& File, 2005; Turner et al., 2003). It might also be especially effective in healthy but sleep deprived users (Baranski, 2004). Ritalin has been shown to augment problem-solving, various memory functions, and selective attention (Elliott et al., 1997; Linssen et al., 2012; Mehta et al., 
2000). Yet, for the most part these studies report limited, if any, practical performance benefits. For example, one systematic review of the common CEDs methylphenidate and modafinil, found little evidence to confirm their efficacy for healthy users (Repantis et al., 2010). No strong effects were confirmed for the former, although the drug was associated with a small benefit in terms of spatial working memory. For the latter, some attentional enhancement was observed, but no impact was specified on memory, mood or motivation. According to one pharmacological review of WADA's banned stimulants, only two substances, meclofenoxate and phenylpiracetam, were considered to have cognitive enhancing actions (Docherty, 2008). The remainder, including amphetamine-like methylphenidate, were classified as monoaminomimetic agents, which act without likely cognitive advantage beyond the familiar effects on alertness. Amongst WADA's other banned, specified stimulants, Alzheimer medication meclofenoxate may aid in recovery from fatigue (Haavisto, 2011). The non-specified piracetam analog, phenylpiracetam, has been linked to Russian use, initially by cosmonauts due to its reported memory-enhancing effects (Malykh \& Sadaie, 2010). While phenylpiracetam appears on the WADA banned list, other forms of racetams do not; nevertheless, given their similar chemical structure, their use would likely incur similar penalties for transgressing athletes.

Of the more renowned CEDs, WADA's prohibition of modafinil seems premised on its potential stimulatory physical rather than mental impact. Some suggestive evidence offers support, but decisive evidence of the drug's usefulness for either is still lacking. Medical judgement recommends modafinil for treating the sleep disorder narcolepsy (European Medicines Agency, 2017). Meanwhile, news broadcaster BBC reported that the British Army has tested modafinil along with numerous other stimulants as a method of sustaining soldiers' alertness (BBC, 2017). Given the drug's utility in combating sleep disorders, modafinil has been considered for use by astronauts facing disrupted sleep brought about by swift day / 
night transitions (Thirsk et al., 2009). Popular awareness that prominent institutions are evaluating the use of CEDs like modafinil have only added to its attractiveness for athletes (Repantis et al., 2010).

Drawing firm conclusions based on CEDs studies is complicated by several confounding methodological variables. To begin with, a universally accepted standard testing protocol for evaluating the effects of CEDs on healthy individuals does not exist, which means that comparisons between studies remains problematic. A second problem revolves around dosages and timing. Again, no benchmark guides clinical dosages (Maslen, Faulmüller \& Savulescu, 2014; Repantis et al., 2010), repeated application, the differences between short- and long-term impacts on brain chemistry (Husain \& Mehta, 2011), and cognitive performance. A further problem has to do with the potential for CEDs to deliver non-linear effects (de Jonge et al., 2008). Impact upon one aspect of cognitive performance might therefore have implications for another aspect, and may change with dosage and repetition.

\section{Risk and Polysubstance Use: The Brain-Body Link}

There is insufficient, high-quality, longitudinal evidence to make conclusive statements about the risks of CED use (Godfrey, 2009; Tully, Montgomery, Maier \& Sumnall, 2019), including their safety with respect to different drugs, combinations, dosages, and repeated use over the long-term (Cakic, 2009). The two primary concerns are: (1) polysubstance use, and (2) addiction or dependency.

Polysubstance use refers to the concurrent use of multiple illicit or medical substances over a period of time. Polysubstance users typically demonstrate worse mental health than the rest of the population and are at greater risk of developing physiological or psychiatric conditions (Connor, Gullo, White \& Kelly, 2014). Evidence is lacking about the effects of 
CEDs polysubstance use, either with multiple substances for enhancement, or other recreational or performance-enhancing substances. However, there is research to suggest that polysubstance use does occur alongside CEDs use (e.g. McCabe, Knight, Teter \& Wechsler, 2005; Vargo \& Petroczi, 2016; Wolff \& Brand, 2013).

Addiction to stimulants, and in particular stimulants used for medical purposes (e.g., methylphenidate), has received some research attention (Gahr, Freudenmann, Hiemke, Köllea \& Schönfeldt-Lecuonaa, 2014). Data support the possibility that misuse of CEDs, especially medically prescribed and illicit substances, presents the potential for physiological addiction and psychological dependency (Volkow \& Swanson, 2003). While these two primary concerns require further evidence, is should be noted that the ambiguous effectiveness of CEDs probably makes the risk to reward trade-off unfavourable (Heinz, Kipke, Heimann \& Wiesing, 2012).

Although too early to suggest that a correlation can be found between body and braindoping, further studies on this relationship seem worthwhile (Dietz et al., 2013). For example, individuals with a history of illegal substance use report higher levels of nonmedical pharmaceutical cognitive enhancer use as well (Maier et al., 2016). According to Bacharach, Bamberge and Sonnenstuhl (2002), some employees explain their CEDs use as a method to combat perceived work stress. Similarly, McCabe et al. (2005) found that the most significant predictor of non-medical PCE use by college students was the difficulty of admissions criteria. A study of German university students concluded that higher levels of chronic stress was associated with PCE use (Sattler, 2019). In sport, stress and competitive levels may also contribute to CED use given its extreme, competitive nature.

Although controlled for in clinical studies, a further complication might arise with unexpected interactions with other substances in a user's system. Healthy individuals taking CEDs are not under medical guidance and may be vulnerable to counter-indicated substances 
(Cleveland, 2016), especially when dosages are self-determined. Users may also be subject to unexpected side-effects, as little can be confirmed about the implications of long-term consumption and/or high dosages. For example, ADHD drug methylphenidate has been connected to a suite of side effects including headaches, seizures, hypertension, cardiac arrest, anxiety, depression, and anaphylactic reaction (Frati et al., 2015).

\section{Implications for Sport and Anti-doping Policy}

\section{Code Violations}

Testing for performance-enhancing drugs was introduced at the Mexico Olympic Games in 1968 in response to a rapid escalation in the use of stimulants and AAS across elite sport, especially in Eastern Europe (Hunt, 2007). Although the International Olympic Committee (IOC) promptly released a list of prohibited substances and methods, it was not until a series of high-profile incidents in world sport, including questionable East German athlete performances, the scandal embroiling Canadian sprinter Ben Johnson at the 1988 Olympics, doping allegations at the 1996 Olympic Games, and reports of widespread drug use in the Tour de France, that WADA was established as the anti-doping global watchdog in 1999 (Hanstad, Smith \& Waddington, 2008).

WADA has since assumed responsibility for harmonising anti-doping rules across the world of sport, principally through the specification of a 'Code' outlining prohibited substance use and methods, in and out of competition testing of athletes, and the imposition of sanctions and penalties for transgressions (see WADA, 2020). As first principles, WADA aims to 'level the playing field' by precluding the unfair use of PEDs (Pampel, 2007), while also protecting the integrity of sport along with the health of its participants. Consequently, the drugs-in-sport problem has focused on removing unfair advantages, protecting athlete 
health, and safeguarding sport's reputation. With these three ambitions in mind, it is not difficult to see why WADA has recently targeted prescription CEDs.

Despite uncertainties about the effects of CEDs, or perhaps because of them, WADA has outlawed a range of substances associated with cognitive enhancement, having placed them within the prohibited Code. The WADA Code details a list of prohibited substances including the high-profile performance enhancement suspects like erythropoietin (EPO) and related drugs that increase the oxygen carrying capacity of the blood, human growth hormone, AAS, the more powerful anti-inflammatory drugs, and stimulants, as well as a range of non-performance enhancing but illicit drugs like cannabis, ecstasy, and cocaine. There is also provision for an exemption for athletes who can demonstrate that they must use a banned drug for therapeutic purposes. In these instances, athletes with a documented medical condition that requires the use of a prohibited substance or method can request an exemption from their national anti-doping agency and national sport governing body. WADA (2019) accepts that athletes may have legitimate illnesses or conditions that require the use of medications that are on the prohibited list and allows for these to be used under strict guidelines.

In order to be proscribed by the Code, drugs must meet two of the following three criteria. First, the drug demonstrably enhances performance. Second, consumption constitutes a risk to the athlete's health. Finally, use violates 'the spirit of sport'. WADA defined this third criterion as the celebration of the human spirit and related positive features in competitive sport like fun and joy, courage, teamwork, pure excellence in performance, respect for the rules and other participants, dedication and commitment, character and education, community and solidarity, as well as ethics, fair play and honesty. This suite of values conflates to the WADA slogan of 'play-true'. 
WADA chose to locate CEDs within the existing Code by prohibiting the classes of stimulants during competition that might affect cognition as well as physiological arousal. Approximately 70 stimulants fall under the 'S6' category, with the additional stipulation that other substances of a similar chemical composition are also outlawed (WADA, 2020). Amongst the lengthy list, methylphenidate receives attention as a so-called specified substance, a term that denotes more discretion with transgression penalties where WADA acknowledges a greater possibility that the substance can be consumed inadvertently. In contrast, the CED modafinil is a non-specified substance. A two-year maximum ban accompanies the use of the former, and a four-year maximum for the latter. Whether their prohibition has any effect on the propensity for tested or non-tested athletes to take them remains unclear (Cakic, 2009).

\section{Pinpointing the CEDs 'Policy Problem'}

Elite sport faces at least two different kinds of doping policy problems. The first relates to the use of PEDs most often associated with cheating in sport, including for example, AAS and allied hormones, stimulants, prescription analgesics, endurance 'blood boosters', and masking agents for concealing use. The non-medical use of many PEDs such as these can both enhance performance and risk health (Parisotto, 2006; Savulescu, Foddy \& Clayton, 2004). The second problem relates to the use of illicit drugs by athletes for recreational purposes, and possibly, recovery. While illicit drugs mostly undermine performance, their abuse can compromise an athlete's physical and mental health (SAMHSA, 2008).

Part of the CEDs policy challenge for sport regulators concerns the potentially wideranging substances that might be described as cognitive enhancing. Based on previous research, Maier and Schaub (2015) used the term neuroenhancement to refer to the 'misuse of prescription drugs, other illicit drugs, or alcohol for the purpose of enhancing cognition, 
mood, or prosocial behaviour in academic or work-related contexts' (p. 2). Inclusive definitions, like the previous, mean that CEDs can include legal (e.g., caffeine), medically controlled (e.g., methylphenidate) and illicit (e.g., cocaine) substances (Garasic \& Lavazza, 2016; Maier, Liechti, Herzig \& Schaub, 2013), all of which putatively deliver cognitive or neuroenhancements in the form of improved focus, concentration, alertness, and rapid decision-making.

At the same time as protecting the integrity of elite sport, WADA policy aims to safeguard the health of athletes. Despite limited evidence examining the potential negative health effects of CEDs use for enhancement, related behaviours such as polysubstance use and online sourcing of controlled substances are relevant concerns, as is the absence of studies investigating long-term effect and addiction or dependency in healthy populations (Tully et al., 2019). As we have noted, studies of university students, considered at-risk given the benefits of cognitive enhancement to academic performance in concert with the performance-oriented environment, indicate usage rates between $1-20 \%$ depending on the methodology used (Dietz, Soyka \& Franke, 2016). The similarities between the pressures that drive students towards enhancement, and the environment of elite-sport is supported by evidence that students who have competed in elite sport are more likely to view cognitive enhancement favourably and use CEDs to improve athletic performance (Ford, 2008; Gallucci \& Martin, 2015; Vargo et al., 2014). Yet, the presumed effects of CED substances remains contested as previous research has mostly been limited by varied study design and multiple constraining variables that influence drug efficacy (e.g., Advokat \& Scheithauer, 2013; Caviola \& Faber, 2015; d'Angelo, Savulich \& Sahakian, 2017; Fond et al., 2015). Further, early evidence suggests that CED users cannot be differentiated from non-users in regard to level of achievement or performance, which foreshadows the risk that all levels of athletes could be attracted to their consumption (Lazarus et al., 2017). 
Against a policy backdrop attuned to remove 'cheating' through drug-inspired artificial advantages, while protecting both sport's good standing and athlete health, it is not immediately apparent where CEDs fit in (Cleveland, 2016). Assumptions about natural human limitations tend to be continually reset as new levels of performance are continually established (Wagner, Robinson \& Weibking, 2015). Escalating standards have further been fuelled by defensive doping, where athletes choose to employ PEDs based on the ironic assumption that it will level the playing field because their competitors are already using banned substances. A similar possibility has been foreshadowed with CEDs (Farah et al., 2004). A CEDs study with university students, for example, suggested that a defensive contagion effect is a real possibility when perceptions of use by others increases (Sattler et al., 2013). A recent online ethnographic study found that New York college students using CEDs were confused and uncertain about the dosages to take, the beneficial effects, the potential risks, and the side-effects (Petersen, Enghoff \& Demant, 2019). In consequence, the students had developed a 'folk pharmacology' of CEDs as a form of decision-making heuristic in order to navigate their own inability to make informed choices.

\section{Efficacy and Evidence Issues}

Additional evidence will be needed to determine if CEDs do in fact deliver benefits that can provide an unfair advantage to elite athletes for whom even incremental improvements are attractive. While WADA concerns itself with the potential for athletes to acquire 'unnatural' advantages, determining what exactly constitutes a 'natural' cognitive benchmark (e.g. Greely et al., 2008) for athletes is not as easy as with PEDs, where for example, a testosterone to epi-testosterone ratio can be measured. WADA's position on cognitive enhancers relies on their default prohibition of pharmaceutical stimulants, leaving elite athletes vulnerable to uncertainties about what is permissible and what is not (Docherty, 
2008), especially since stimulants are mainly banned in-competition because their effects are relatively fleeting (Kimko, Cross \& Abernethy, 1999). Furthermore, WADA's prohibitions can only go so far as CEDs are subject to different regulatory restrictions in sporting competitions that are not signatories to WADA compliance (Dubljević \& Ryan, 2015).

The utility of CEDs to lower level and recreational athletes appears ambiguous, while the usefulness to top flight coaches and other specialist sport analysts would fit into the same category as healthy students, and professionals or executives aiming for a boost in concentration, alertness, memory, and fatigue resistance. In addition, the use of CEDs demands a minimum level of economic privilege to begin with, given the costs associated with non-prescription, non-subsidised use (Ketchum et al., 2017). As Imperatori, Milbourn and Garasic (2018) observed, the more expensive the drug, the more advantage it provides to those with the means to acquire it.

While WADA reasonably worries about enhancement by the self-interested athlete seeking an (unfair) advantage, some commentators have argued that use can be acceptable as long as it does not compromise a zero-sum game, where one athlete's gain is another's loss (Goodman, 2010; Pavarini, McKeown \& Singh, 2018). A further problem has been noted by a growing chorus of commentators concerned that the rapid increase in economic payoffs is compromising esports as its competitors utilise CEDs to gain any possible advantage (Holden, Kaburakis \& Rodenberg, 2018; Sylvester \& Rennie, 2017). The eSports Integrity Coalition identified CEDs doping as a preeminent threat to esport's growth and integrity (Esport Integrity Coalition, 2016).

The nascent evidence points to potentially modest improvements in memory or decision-making for CEDs users. However, more research is needed to understand the mechanisms of effect, as well as the risks associated with prolonged and heavy dosages. Furthermore, if the suggestions of a speed versus accuracy trade-off are confirmed, use for 
many athletes in sports where deeper but delayed thought is unwelcome, would be compromised. CEDs could also lead to other positive or negative interference in cognitive processes and physical performance. The risks go beyond the physical as well. Davis (2017), for example, proposed a taxonomy of harms incorporating the biological, ethical and societal. Despite the lack of confirmatory performance enhancing evidence, CEDs are likely to attract experimentation by athletes, already attentive to the promise held in new practices from training methods to dietary and nutritional supplements (Thompson, 2012). Even if CEDs do not unfairly improve athletic and physical performance, it might be reasonable to speculate that drugs capable of delivering more efficacious cognitive enhancing effects will arrive sooner or later. Further, as Dresler et al. (2019) foreshadowed, genetic modifications aimed at augmenting learning and memory processes have been demonstrated in animal models, and might provide a glimpse into the future of human cognitive enhancement.

Elite athletes might be particularly attracted to CEDs banned only in-competition, as the putative opportunity to enhance the effectiveness of training sessions could also be complemented by improved recovery from the innumerable hours of heavy concentration and tension inherent in many elite sports. If CEDs work, they would assuredly be beneficial for managing performance or game analysis, pre-performance anxiety, tactical preparation, and travel-interrupted sleep. Successful sporting performance is predicated upon effective training, which can translate into superior competitive execution. In theory, efficacious CEDs would yield advantages in terms of learning, memory and concentration for athletes who must coalesce their training into split-second decisions under pressure on the field of play.

Since WADA only bans stimulants during in-competition activities, elite athletes might feel free to experiment with CEDs during lengthy training or preparatory periods, or during times of excessive fatigue and sleep deprivation (Battleday \& Brem, 2015). Of course, elite coaches are not subject to anti-doping tests at all, while non-tested elite athletes and 
recreational athletes face no structural impediments either. Coveney, Williams and Gabe (2019) noted that regulatory policies around CEDs need to deliver a nuanced response, which in turn demands a 'proactionary' rather than a reactionary approach. One nuance, for example, might consider the likelihood of systemic doping where high-performance teams recruit doctors to administer CEDs. Another might take a risk minimisation approach based on assumptions of 'managed technological optimism', where the risk to benefit ratio of using CEDs can be optimised under active medical oversight (Jwa, 2019).

\section{Concluding Comments}

CEDs for cognitive enhancement in sporting performance is probably occurring at similar rates to other groups subjected to high stress, performance-oriented environments (e.g., students, medical professionals). The propensity for elite athletes to be attracted to CEDs is significant given the conceivable benefits to athlete performance and the potential health concerns associated with polysubstance use and addiction, in addition to the potential for violating the anti-doping code and securing an unfair advantage. Although the evidence for CEDs efficacy remains conflicted (e.g., Caviola \& Faber, 2015; d'Angelo, Savulich \& Sahakian, 2017; Fond et al., 2015), at-risk populations in stressful performance-oriented environments (e.g., student athletes) demonstrate increasing awareness and use of CEDs for non-medical cognitive enhancement (e.g., Dietz et al., 2013; Lazarus, Ypsilanti, Lamprou \& Kontogiorgis, 2017; Maier et al., 2013; McCabe et al., 2014).

While CEDs present a potential threat to sport integrity, their current acceptance both inside and outside of elite sporting competition is unclear (Conrad, Humphries \& Chatterjee, 2019; Partridge et al., 2012). Considered in light of the limited research into the potential health effects, the high-pressure environment of elite sport, and the low public acceptance of pharmaceutics for enhancing sport performance, artificial cognitive enhancement represents a 
neglected and worrying issue for anti-doping authorities and sport policy-makers. Previous studies also reinforce the importance of understanding the dynamic environmental factors, such as working culture and performance pressures, that are critical to controlling dopingsubstance use related attitudes and behaviours (Blank, Kopp, Niedermeier, Schnitzer \& Schobersberger, 2016; Kirby, Moran \& Guerin, 2011; Petroczi \& Aidman, 2008; Smith et al., 2010; Zucchetti, Candela \& Villosio, 2015). Lucke, Bell, Partridge and Hall (2011) commented that "neuroenhancing drugs should be assessed on their merits, and regulated according to the risks that they pose and the feasibility of regulating or restricting their use' (p. 201). Given that use is a problem in sport as well as society, and that the efficacy and risks of CED use are complex and ambiguous, the collection of further evidence is integral to creating and progressing effective evidence-based sport policy (Chatwin, Measham, O’Brien \& Sumnall, 2017; Forlini, \& Hall, 2016).

\section{Disclosure of Interest}

This commentary was funded by the Alcohol and Drug Foundation, Australia. 


\section{References}

Adler, D. (2018). MLB releases annual report on PED testing

Retrieved from https://www.mlb.com/news/mlb-releases-annual-report-on-ped-testingc301312524

Advokat, C. D., \& Scheithauer, M. (2013). Attention-deficit hyperactivity disorder (ADHD) stimulant medications as cognitive enhancers. Frontiers in Neuroscience, 7(82), 1-12.

Bacharach, S. B., Bamberger, P. A., Sonnenstuhl, W. J. (2002). Driven to drink: Managerial control, work-related risk factors, and employee problem drinking. Academy of Management Journal, 45, 637-658.

Bagot, K. S., \& Kaminer, Y. (2014). Efficacy of stimulants for cognitive enhancement in non-attention deficit hyperactivity disorder youth: a systematic review. Addiction, 109(4), 547-557.

Baldwin, A. (2019) Targeted doping tests having an impact in esports, says Verroken.

Retrieved from https://uk.reuters.com/article/uk-sport-doping/targeted-doping-tests-havingan-impact-in-esports-says-verroken-idUKKCN1RT2EX

Baranski, J. V., Pigeau, R., Dinich, P., \& Jacobs, I. (2004). Effects of modafinil on cognitive and meta-cognitive performance. Human Psychopharmacology: Clinical and Experimental, 19(5), 323-332.

Battleday, R. M., \& Brem, A. K. (2015). Modafinil for cognitive neuroenhancement in healthy non-sleep-deprived subjects: A systematic review. European Neuropsychopharmacology, 25(11), 1865-1881.

BBC (2017). http://news.bbc.co.uk/2/hi/uk_news/politics/6083840.stm - accessed November $25,2017$. 
Cakic, V. (2009). Smart drugs for cognitive enhancement: Ethical and pragmatic considerations in the era of cosmetic neurology. Journal of Medical Ethics, 35, 611615.

Caldenhove, S., Sambeth, A., Sharma, S., Woo, G., \& Blokland, A. (2018). A combination of nootropic ingredients $(\mathrm{CAF}+)$ is not better than caffeine in improving cognitive functions. Journal of Cognitive Enhancement, 2(1), 106-113.

Campbell-Meiklejohn, D., Simonsen, A., Scheel-Krüger, J., Wohlert, V., Gjerløff, T., Frith, C.D., Rogers, R.D., Roepstorff, A. \& Møller, A. (2012). In for a penny, in for a pound: methylphenidate reduces the inhibitory effect of high stakes on persistent risky choice. Journal of Neuroscience, 32(38), 13032-13038.

Caviola, L., \& Faber, N. S. (2015). Pills or push-ups? Effectiveness and public perception of pharmacological and non-pharmacological cognitive enhancement. Frontiers in Psychology, 6, 1852.

Chatterjee, A. (2007). Cosmetic neurology and cosmetic surgery: Parallels, Predictions, and Challenges. Cambridge Quarterly of Healthcare Ethics, 16, 129-137.

Chatwin, C., Measham, F., O’Brien, K., \& Sumnall, H. (2017). New drugs, new directions? Research priorities for new psychoactive substances and human enhancement drugs. International Journal of Drug Policy, 40, 1-5.

Cleveland, E. (2016). What's missing from the current smart drugs debate? Society, 53(3), 237-239.

Conant-Norville D.O., \& Tofler I.R. (2005). Attention deficit/hyperactivity disorder and psychopharmacologic treatments in the athlete. Clinical Sports Medicine, 24, 829-843.

Connor, J. P., Gullo, M. J., White, A., \& Kelly, A. B. (2014). Polysubstance use: Diagnostic challenges, patterns of use and health. Current Opinion in Psychiatry, 27(4), 269-275. 
Conrad, E. C., Humphries, S., \& Chatterjee, A. (2019). Attitudes toward cognitive enhancement: the role of metaphor and context. AJOB Neuroscience, 10(1), 35-47.

Copani, A., Genazzani, A.A., Aleppo, G., Casabona, G., Canonico, P.L., Scapagnini, U., Nicoletti, F. (1992). Nootropic drugs positively modulate alpha-amino-3-hydroxy-5methyl-4-isoxazolepropionic acid-sensitive glutamate receptors in neuronal cultures, Journal of Neurochemistry 58(4), 1199-1204.

Coveney, C., Williams, S. J., \& Gabe, J. (2019). Enhancement imaginaries: Exploring public understandings of pharmaceutical cognitive enhancing drugs. Drugs: Education, Prevention and Policy, 26(4), 319-328.

d'Angelo, L., Camilla, S., Savulich, G., \& Sahakian, B. J. (2017). Lifestyle use of drugs by healthy people for enhancing cognition, creativity, motivation and pleasure. British Journal of Pharmacology, 174(19), 3257-3267.

Davis, N. J. (2017). A taxonomy of harms inherent in cognitive enhancement. Frontiers in Human Neuroscience, 11(63), 1-9.

de Jonge, R., Bolt, I., Schermer, M., \& Olivier, B. (2008). Botox for the brain: Enhancement of cognition, mood and pro-social behavior and blunting of unwanted memories. Neuroscience and Biobehavioral Reviews, 32, 760-776.

Dietz, P., Soyka, M., \& Franke, A. G. (2016). Pharmacological neuroenhancement in the field of economics-Poll results from an online survey. Frontiers in Psychology, 7, 520.

Dietz, P., Ulrich, R., Dalaker, R., Streigel, H., Franke, A.G., Lieb, K., \& Perikles, S. (2013). Associations between Physical and Cognitive Doping - A Cross-Sectional Study in 2,997 Triathletes, PLOS One, 8(11), e78702 doi:10.1371/journal.pone.0078702

Docherty, J.R. (2008). Pharmacology of stimulants prohibited by the World Anti-Doping Agency (WADA), British Journal of Pharmacology, 154, 606-622. 
Dresler M., Sandberg A., Bublitz C., Ohla K., Trenado C., Mroczko-Wasowicz A., Kuhn, S. \& Repantis, D. (2019). Hacking the brain: Dimensions of cognitive enhancement. ACS Chemical Neuroscience, 10, 1137-1148.

Dubljević, V., \& Ryan, C. J. (2015). Cognitive enhancement with methylphenidate and modafinil: conceptual advances and societal implications. Neuroscience and Neuroeconomics, 4, 25-33.

Elliott, R., Sahakian, B.J., Matthews, K., Bannerjea, A., Rimmer, J., \& Robbins, T.W. (1997). Effects of methylphenidate on spatial working memory and planning in healthy young adults. Psychopharmacology, 131(2), 196-206.

Esport Integrity Coalition (2016). Threats to integrity of eSports: A risk assessment. London: ESIC: $1-13$.

Farah, M.J., Illes, J., Cook-Deegan, R., Gardner, H., Kandel, E., King, P., Parens, E., Sakakian, B., \& Wolpe, P.R. (2004). Neurocognitive enhancement: What can we do and what should we do? Nature Reviews Neuroscience, 5, 421-425.

Fédération Internationale des Échecs [FIDE] (2018). FIDE Anti-Doping Rules based on Wada's Models of Best Practice for International Federations and the World AntiDoping Code. Valid from 1.1.2015, Updated 2018. Accessed May 8, 2020: https://handbook.fide.com/files/handbook/FIDEAntiDopingRules.pdf

Ferretti, A., \& Ienca, M. (2018). Enhanced cognition, enhanced self? On neuroenhancement and subjectivity. Journal of Cognitive Enhancement, 2(4), 348-355.

Fond, G., Micoulaud-Franchi, J. A., Brunel, L., Macgregor, A., Miot, S., Lopez, R., ... \& Repantis, D. (2015). Innovative mechanisms of action for pharmaceutical cognitive enhancement: a systematic review. Psychiatry Research, 229(1-2), 12-20.

Ford, J. A. (2008). Nonmedical prescription drug use among college students: A comparison between athletes and nonathletes. Journal of American College Health, 57(2), 211-220. 
Franke, A. G., Bagusat, C., Rust, S., Engel, A., \& Lieb, K. (2014). Substances used and prevalence rates of pharmacological cognitive enhancement among healthy subjects. European Archives of Psychiatry and Clinical Neuroscience, 264(1), 83-90.

Franke, A.G., Bonertz, C., Christmann, M., Huss, M., Fellgiebel, A. Hildt, E., \& Lieb, K. (2010). Non-medical use of prescription stimulants and illicit use of stimulants for cognitive enhancement in pupils and students in Germany. Pharmacopsychiatry, 44, 60-66.

Franke, A.G., Gransmark, P., Agricola, A., Schuhle, K., Rommel, T., Sebastian, A., Ballo H.E., Gorbulev, S., Gerdes, C., Frank, B., Ruckes, C., Tuscher, O. \& Lieb K. (2017). Methylphenidate, modafinil, and caffeine for cognitive enhancement in chess: A double-blind, randomised controlled trial, European Neuropsychopharmacology, 27(3), 248-260.

Frati, P., Kyriakou, C., Del Rio, A., Marinelli, E., Vergallo, G.M., Zami, S., \& Busardò, F.P. (2015). Smart drugs and synthetic androgens for cognitive and physical enhancement: Revolving doors of cosmetic neurology. Current Neuropharmacology, 13(1), 5-11.

Froestl, W., Muhs, A., \& Pfeifer, A. (2012). Cognitive enhancers (nootropics). Part 1: Drugs interacting with receptors. Journal of Alzheimer's Disease, 32, 793-887.

Gahr, M., Freudenmann, R. W., Hiemke, C., Kölle, M. A., \& Schönfeldt-Lecuona, C. (2014). Abuse of methylphenidate in Germany: data from spontaneous reports of adverse drug reactions. Psychiatry Research, 215(1), 252-254.

Gallucci, A. R., \& Martin, R. J. (2015). Misuse of prescription stimulant medication in a sample of college students: Examining differences between varsity athletes and nonathletes. Addictive Behaviors, 51, 44-50. 
Garasic, M. D., \& Lavazza, A. (2016). Moral and social reasons to acknowledge the use of cognitive enhancers in competitive-selective contexts. BMC Medical Ethics, 17(1), 112.

Gilbert, B. (2015). Here's why Adderall is taking over the world of professional gaming. Retrieved from https://www.businessinsider.com/how-adderall-is-used-in-esports2015-7? $\mathrm{r}=\mathrm{US} \& \mathrm{IR}=\mathrm{T}$

Giurgea, C., \& Salama, B. (1977). Nootropic drugs, Progress in NeuroPsychopharmocology. 1(3/4), 235-247.

Godfrey, J. (2009). Safety of therapeutic methylphenidate in adults: a systematic review of the evidence. Journal of Psychopharmacology, 23(2), 194-205.

Goodman, R. (2010). Cognitive enhancement, cheating, and accomplishment. Kennedy Institute of Ethics Journal, 20, 145-160.

Greely, H., Sahakian, B., Harris, J., Kessler, R. C., Gazzaniga, M., Campbell, P., \& Farah, M. J. (2008). Towards responsible use of cognitive-enhancing drugs by the healthy. Nature, 456(7223), 702-705.

Haavisto, M. (2011). Reviving the Broken Marionette: Treatments for CFS/ME and Fibromyalgia, Self-Published.

Hanstad, D., Smith, A. and Waddington, I. (2008). The establishment of the World AntiDoping Agency: A study of the management of organizational change and unplanned outcomes'. International Review for the Sociology of Sport, 43 (4), 227-249.

Heinz, A., Kipke, R., Heimann, H., \& Wiesing, U. (2012). Cognitive neuroenhancement: false assumptions in the ethical debate. Journal of Medical Ethics, 38(6), 372-375.

Holden, J. T., Kaburakis, A., \& Rodenberg, R. M. (2018). Esports: Children, stimulants and video-gaming-induced inactivity. Journal of Paediatrics and Child Health, 54(8), 830-831. 
Holden, J. T., Rodenberg, R. M., \& Kaburakis, A. (2017). Esports corruption: Gambling, doping, and global governance. Maryland Journal of International Law, 32(1), 236273.

Hunt, T. (2007) Sports, drugs and the Cold War: The conundrum of Olympic doping policy 1970-1979. Olympika: The International Journal of Olympic Studies International Centre for Olympic Studies, London: Canada: 19-41.

Husain, M., \& Mehta, M.A. (2011). Cognitive enhancement by drugs in health and disease. Trends in Cognitive Science, 15(1), 28-36.

Imperatori, L. S., Milbourn, L., \& Garasic, M. D. (2018). Would the use of safe, costeffective tDCS tackle rather than cause unfairness in sports? Journal of Cognitive Enhancement, 2(4), 377-387.

Jwa, A. S. (2019). Regulating the use of cognitive enhancement: An analytic framework. Neuroethics, 12, 293-309.

Kessler, R.C., Adler, L., Barkley, R., Biederman, J., Conners, C.K., Demler, O., Faraone, S.V., Greenhill, L.L., Howes, M.J., Secnik, K. and Spencer, T. (2006). The prevalence and correlates of adult ADHD in the United States: results from the National Comorbidity Survey Replication. American Journal of Psychiatry, 163(4), pp.716-723.

Ketchum, F. B. (2017). Commentary: Care, choice, and the ethical imagination. Cambridge Quarterly of Healthcare Ethics, 26(4), 698-700.

Kimko, H.C., Cross, J.T., Abernethy, D.R. (1999). "Pharmacokinetics and clinical effectiveness of methylphenidate". Clinical Pharmacokinetics, 37(6): 457-470.

Lakhan, A.E., \& Kirchgessner, A. (2012). Prescription stimulants in individuals with and without attention deficit hyperactivity disorder: misuse, cognitive impact, and adverse effects, Brain and Behavior, 2(5) 661-677. 
Lazuras, L., Ypsilanti, A., Lamprou, E., \& Kontogiorgis, C. (2017). Pharmaceutical Cognitive Enhancement in Greek University Students: Differences Between Users and Non-Users in Social Cognitive Variables, Burnout, and Engagement. Substance Use \& Misuse, 52(7), 950-958.

Linssen, A., Vuurman, E., Sambeth, A., \& Riedel, W. (2012). Methylphenidate produces selective enhancement of declarative memory consolidation in healthy volunteers. Psychopharmacology, 221(4), 611-619.

Lucke, J. C., Bell, S. K., Partridge, B. J., \& Hall, W. D. (2011). Academic doping or Viagra for the brain?. EMBO Reports, 12(3), 197-201.

Maher, B. (2008). Poll results: Look who's doping. Nature, 452, 674-675.

Maier, L. J., \& Schaub, M. P. (2015). The use of prescription drugs and drugs of abuse for neuroenhancement in Europe. European Psychologist, 20, 155-166.

Maier, L. J., Ferris, J. A., \& Winstock, A. R. (2018). Pharmacological cognitive enhancement among non-ADHD individuals - a cross-sectional study in 15 countries. International Journal of Drug Policy, 58, 104-112.

Maier, L. J., Haug, S., \& Schaub, M. P. (2016). Prevalence of and motives for pharmacological neuroenhancement in Switzerland - Results from a national internet panel. Addiction, 111(2), 280-295.

Maier, L. J., Liechti, M. E., Herzig, F., \& Schaub, M. P. (2013). To dope or not to dope: neuroenhancement with prescription drugs and drugs of abuse among Swiss university students. PloS one, 8(11), e77967.

Malykh, A.G., Sadaie, M.R. (2010) Piracetam and Piracetam-like drugs from basic science to novel clinical applications to CNS disorders, Drugs, 70(3), 287-312. 
Maslen, H., Faulmüller, N., \& Savulescu, J. (2014). Pharmacological cognitive enhancement - how neuroscientific research could advance ethical debate. Frontiers in Systems Neuroscience, 8(107), 1-12.

McCabe, S. E., Knight, J. R., Teter, C. J., Wechser, H. (2005). Non-medical use of prescription stimulants among US college students: Prevalence and correlates from a national survey. Addiction, 100, 96-106.

McCabe, S. E., West, B. T., Teter, C. J., \& Boyd, C. J. (2014). Trends in medical use, diversion, and nonmedical use of prescription medications among college students from 2003 to 2013: Connecting the dots. Addictive Behaviors, 39(7), 1176-1182.

McCabe, S.E., \& West, B.T. (2013). Medical and nonmedical use of prescription stimulants: Results from a national multicohort study. Journal of the American Academy of Child and Adolescent Psychiatry. 52(12), 1272-1280.

Mehta, M. A., Owen, A. M., Sahakian, B. J., Mavaddat, N., Pickard, J. D., \& Robbins, T. W. (2000). Methylphenidate enhances working memory by modulating discrete frontal and parietal lobe regions in the human brain. Journal of Neuroscience, 20(6), RC65RC65.

Mihailov, E., \& Savulescu, J. (2018). Social policy and cognitive enhancement: Lessons from chess. Neuroethics, 11(2), 115-127.

Pampel, F. (2007) Drugs and Sport. Infobase Publishing: New York.

Parisotto, R. (2006) Blood Sports: The Inside Dope on Drugs in Sport. South Yarra, Victoria: Hardie Grant Books.

Partridge, B., Lucke, J., \& Hall, W. (2012). A Comparison of Attitudes Toward Cognitive Enhancement and Legalized Doping in Sport in a Community Sample of Australian Adults, AJOB Primary Research, 3(4) 81-86. 
Partridge, B.J., Bell, S.K., Lucke, J.C., Yeates, S., \& Hall, W.D. (2011). Smart drugs as “common as coffee": Media hype about neuroenhancement. PLoS One, 6(11), e28416. doi:10.1371/journal.pone.0028416.

Patra, K. (2013). Richard Sherman: I was misquoted about Adderall use. Retrieved from http://www.nfl.com/news/story/0ap1000000159155/article/richard-sherman-i-was$\underline{\text { misquoted-about-adderall-use }}$

Pavarini, G., McKeown, A. \& Singh, I. (2018). Smarter than thou, holier than thou: The dynamic interplay between cognitive and moral enhancement. Frontiers in Pharmacology, 9(1189), 1-13.

Peck, S., Vida, M. \& Eccles, S. (2008) Adolescent pathways to adulthood drinking: sport activity involvement is not necessarily risky or protective, Addiction, 103 (supplement 1), 69-83.

Petersen, M. A., Enghoff, O., \& Demant, J. (2019). The uncertainties of enhancement: A mixed-methods study on the use of substances for cognitive enhancement and it's unintended consequences. Performance Enhancement \& Health, 6(3-4), 111-120.

Prudhomme White, B., Becker-Blease, K.A., \& Grace-Bishop, K. (2006). Stimulant medication use, misuse, and abuse in an undergraduate and graduate student sample. Journal of American College Health, 54(5), 261-268.

Ram, S., Hussainy, S., Henning, M., Jensen, M., \& Russell, B. (2016). Prevalence of cognitive enhancer use among New Zealand tertiary students. Drug and Alcohol Review, 35, 345-351.

Randall, D. C., Shneerson, J. M., \& File, S. E. (2005). Cognitive effects of modafinil in student volunteers may depend on IQ. Pharmacology Biochemistry and Behavior, 82(1), 133-139. 
Repantis, D., Schlattmann, P., Laisney, O., \& Heuser, I. (2010). Modafinil and methylphenidate for neuroenhancment in healthy individuals: A systematic review. Pharmacological Research, 62, 187-206.

Riddell, C., Jensen, C., \& Carter, O. (2018). Cognitive Enhancement and Coping in an Australian University Student Sample. Journal of Cognitive Enhancement, 2(1), 6369.

Sachdeva, A., Kumar, K., \& Singh Anand, K. (2015). Non-pharmacological cognitive enhancers: Current perspectives. Journal of Clinical and Diagnostic Research, 9(7), 16.

Sahakian, B. J., Bruhl, A. B., Cook, J., Killikelly, C., Savulich, G., Piercy, T., ... \& Jones, P. B. (2015). The impact of neuroscience on society: cognitive enhancement in neuropsychiatric disorders and in healthy people. Philosophical Transactions of the Royal Society B: Biological Sciences, 370(1677), 20140214.

Santoni de Sio, F., Faulmüller, N., \& Vincent, N. A. (2014). How cognitive enhancement can change our duties. Frontiers in Systems Neuroscience, 8(131), 1-4.

Sattler, S. (2019). Nonmedical use of prescription drugs for cognitive enhancement as response to chronic stress especially when social support is lacking. Stress and Health, $35(2), 127-137$.

Sattler, S., Forlini, C., Racine, E, \& Sauer, C. (2013). Impact of contextual factors and substance characteristics on perspectives toward cognitive enhancement. PLoS One, 8(8), e71452. doi:10.1371/journal.pone.0071452.

Savulecu, J, Foddy, B, Clayton M. (2004) Why we should allow performance enhancing drugs in sport, British Journal of Sports Medicine, 38, 666-670.

Smith, A., Stewart, B., Westberg, K., \& Stavros, C. (2018). Performance and Image Enhancing Drugs and Substances: Issues, Influences and Impacts. Routledge: UK. 
Smith, M.E., \& Farah, M.J. (2011). Are prescription stimulants "smart pills"?: The epidemiology and cognitive neuroscience of prescription stimulant use by normal healthy individuals. Psychological Bulletin, 137(5), 717-741.

Substance Abuse and Mental Health Services Administration [SAMHSA] (2008). Results from the 2007 National Survey on Drug Use and Health (NSDUH). Department of Health and Human Services Office of Applied Studies, Washington D.C.

Sylvester, R., \& Rennie, P. (2017). The world's fastest-growing sport: maximizing the economic success of esports whilst balancing regulatory concerns and ensuring the protection of those involved. Gaming Law Review, 21(8), 625-629.

Thirsk, R., Kuipers, A., Mukai, C., Williams, D. (2009). The space-flight environment: The International Space Station and beyond. CMAJ. 180(12): 1216-1220.

Thompson, H. (2012). Performance Enhancement: Superhuman Athletes. Nature, 487 287289.

Tully, J., Montgomery, C., Maier, L. J., \& Sumnall, H. R. (2019). 9 Estimated prevalence, effects and potential risks of substances used for cognitive enhancement. Human Enhancement Drugs.

Turner, D. C., Robbins, T. W., Clark, L., Aron, A. R., Dowson, J., \& Sahakian, B. J. (2003). Cognitive enhancing effects of modafinil in healthy volunteers. Psychopharmacology, 165(3), 260-269.

Vargo, E. J., \& Petróczi, A. (2016). "It was me on a good day”: exploring the smart drug use phenomenon in England. Frontiers in Psychology, 7, 779.

Vargo, E. J., James, R. A., Agyeman, K., MacPhee, T., McIntyre, R., Ronca, F., \& Petróczi, A. (2014). Perceptions of assisted cognitive and sport performance enhancement among university students in England. Performance Enhancement \& Health, 3(2), 66-77. 
Visser, S.N., Danielson, M.L., Bitsko, R.H., Holbrook, J.R., Kogan, Ghandour, R.M., Perou, R., \& Blumberg, S.J. (2014).Trends in the Parent-Report of Health Care ProviderDiagnosed and Medicated Attention-Deficit/Hyperactivity Disorder: United States, 2003-2011, Journal of the American Academy of Child \& Adolescent Psychiatry, 53(1), 34-46.

Volkow, N. D., \& Swanson, J. M. (2003). Variables that affect the clinical use and abuse of methylphenidate in the treatment of ADHD. American Journal of Psychiatry, 160(11), 1909-1918.

Volkow, N.D., Wang, G.J., Tomasi, D., Kollins, S.H., Wigal, T.L., Newcorn, J.H., Telang, F.W., Fowler, J.S., Logan, J., Wong, C.T. \& Swanson, J.M., (2012). Methylphenidate-elicited dopamine increases in ventral striatum are associated with long-term symptom improvement in adults with attention deficit hyperactivity disorder. Journal of Neuroscience, 32(3), 841-849.

Vrecko, S. (2013). Just how cognitive is "cognitive enhancement"? On the significance of emotions in university students' experiences with study drugs. AJOB Neuroscience, 4(1), 4-12. DOI: 10.1080/21507740.2012.740141

Wagner, N-F, Robinson, J., \& Weibking, C. (2015). The ethics of neuroenhancement: Smart drugs, competition and society. International Journal of Technoethics, 6(1), 10-20.

White, R.D., Harris, G.D., \& Gibson, M.E. (2013). Attention Deficit Hyperactivity Disorder and Athletes, Sports Health, 6(2), 149-156

Wichstrom, T. \& Wichstrom, L. (2009) Does sport participation during adolescence prevent later alcohol, tobacco and cannabis use, Addiction, (104), 138-149.

Wilson, G., M. Pritchard and J. Shaffer (2004) Athletic status and drinking behaviour in colleges students: the influence of gender and coping styles, Journal of American College Health, 52 (3), 269-273. 
Winder-Rhodes, S., Chamberlain,S., Idris,M., Robbins,T., Sahakian, B., Muller,U. (2010). Effects of modafinil and prazosin on cognitive and physiological functions in healthy volunteers, Journal of Psychopharmacology, 24(11),1649-1657.

Wolff, W., \& Brand, R. (2013). Subjective stressors in school and their relation to neuroenhancement: a behavioral perspective on students' everyday life “doping”. Substance Abuse Treatment, Prevention, and Policy, 8(1), 23.

World Anti-Doping Agency [WADA] (2019). International Standard Therapeutic Use Exemptions. Retrieved from https://www.wadaama.org/sites/default/files/resources/files/istue 2019 en new.pdf.

World Anti-Doping Agency [WADA] (2020). International Standard Prohibited List 2020. Retrieved from https://www.wadaama.org/sites/default/files/wada_2020_english_prohibited_list_0.pdf

World Bridge Federation [WBF] (2015). World Bridge Federation [WBF] Anti-Doping Rules, Approved by the Executive Council of the World Bridge Federation at their meeting held on: 15th October 2014, (Based upon the 2015 Code and confirmed by WADA on 17 November 2014), Effective as of 1 January 2015. Accessed May 8, 2020 : http://www.worldbridge.org/rules-regulations/anti-doping-regulations/ 